\title{
Assessment of sustainable development based on the capital approach
}

\author{
Michinori Uwasu*, Helmut Yabar** \\ * Sustainability Design Center, Osaka University \\ 2-1 Yamadaoka, Suita, Osaka, Japan 565-0871 \\ Tel. +81-6-6879-4150 \\ E-mail uwasu@riss.osaka-u.ac.jp
}

\author{
** Graduate School of Life and Environmental Sciences, \\ Sustainable Environmental Studies, University of Tsukuba \\ 1-1-1 Tennodai, Tsukuba, Ibaraki, Japan 305-8572 \\ Te.: +81-2-9853-8836 \\ E-mail: hyabar@jsrsai.envr.tsukuba.ac.jp
}

\begin{abstract}
This study analyzes countries' sustainability conditions using panel data of genuine savings (GS) by calculating the average, trend, and stability of the countries' GS flow. We identify the pattern of GS changes in the past three decades on the basis of these three capital flow measures and the level of capital stock (wealth), and subsequently identify the factors that determine the GS change patterns. We find that the quality of institutional and population growth, along with natural resource abundance, substantially influences capital accumulation in the long term. In particular, our results indicate that only once does a good performance of GS not ensure sustainable development. For example, countries like Kenya performed well in terms of capital accumulation in the first period, but this performance was not maintained in the following period, as a result of the poor quality of institutions and governance. On the contrary, some countries, like Chile, where GS performance was poor in the beginning, eventually achieve a sustained pathway if they have good institutions and governance. In addition, we suggest that even countries in the best performing group for capital change are on an unsustainable path, which will eventually start decreasing in wealth. The exception is Norway, which is socially well developed, but has a lower population density and abundant natural resources. Our study proves that analyzing relevant indicators in the long term is crucial to understanding sustainability.
\end{abstract}

Keywords: sustainable development, genuine savings, institutions/governance, population growth

\section{Introduction}

As global issues such as climate change and financial crisis emerge, more attention is being paid to sustainability. However, given that a wide range of aspects, ranging from environmental degradation and resource depletion to socio-economic issues are involved in sustainability, the assessment of sustainability has become an enduring task. Moreover, the characteristics of sustainability, including dynamics and stochasticity, make any such assessment more difficult. In fact, although numerous indicators and assessment tools for sustainability have been developed and employed, no consensus exists as to which is most appropriate for assessing sustainability. The Environmental Sustainability Index considers a variety of aspects for measuring environmental sustainability at the country level, and for showing the relative status of countries in terms of the environment (Esty et al., 2005). The Ecological Footprint, developed by Wackernagel and Lee (1996), assess the relationship between the consumption level and the earth's carrying capacity. The Human Development Index of the United Nations Development Program (UNDP) addresses the importance of quality of life (QOL), considering income, health, and education of the people. Many other tools, methods, and concepts have been developed and applied to sustainability assessment; see Barry et al., 2007, which effectively summarizes sustainability assessment tools and indicators. These indicators and tools have been widely used in academia and in practice, but independently they capture only limited aspects of sustainability and ignore 
some important features of sustainability. In particular, the main problem with most assessment methods is that they do not explicitly address environmental and socio-economic relations.

The capital approach in economics, when used as a sustainability measurement, argues that as long as we are able to maintain or increase wealth (i.e., capital stock) over time, the goods and services necessary to fulfill human needs will be secured (Pease and Atkinson, 1993; Ekins et al., 2008). The advantage of this approach is that wealth as a product base for human needs includes ecological system services and incorporates dynamic aspects in the assessment (Dasgputa, 2001). Hence, it explicitly takes into account environmental and socio-economic dynamic relations.

Specifically, genuine savings (GS), introduced by Pearce and Atkinson (1993), measure the wealth of nations based on the accumulation of natural capital (e.g., eco services and natural resources), produced capital (i.e., ordinary capital used in economics such as buildings), and human capital (e.g., health and education). The World Bank provides a complete data set of GS for 140 countries and regions over the past 30 years. Moreover, GS is built on the theory of economic growth; a positive GS ensures that consumption by future generations will be non-decreasing (see Dasgupta, 2001 for a mathematical proof of this proposition), which means that it is not necessary to estimate a stream of future consumption to confirm whether the economy is sustainable. With this theoretical foundation, as well as its empirical feasibility, GS can be used as a measurement for sustainable development.

The use of GS as a sustainability indicator has drawn some criticism. One of the major critiques lies in its weak sustainability characteristic, i.e., GS presumes that man-made capital can be substitutable for natural capital (Neumayer, 2010). Also, the empirical estimation issue has been disputed, particularly when estimating natural capital (Pillarisetti, 2005), possibly resulting in overestimation of natural capital stock for some countries. Nevertheless, we believe that analyzing GS indicators in the long term is crucial to understanding sustainability. When it comes to assessment of sustainable development, including less developed countries, transforming natural capital into man-made and human capitals through investment often plays an important role in development for countries at the early stage of development, even if such transformation leads to overconsumption of natural capital. Moreover, this view does not necessarily mean to allow unlimited exploitation of natural capital. In fact, in the discussion section we argue that preserving natural capitals is necessary after a certain level of development has been reached. Regarding the overestimation of natural capital, we indeed show the adverse effect of natural endowment on capital accumulation patterns. In this way, even if measurement errors exist in the indicator, insights into sustainable development could be derived as we will show in this paper.

[Figure 1 here]

However, the technical drawback of this approach is that although GS is an indicator of whether a country is on a sustainable path over a given period, it does not tell us how the values change over time. An example is illustrated in Figure 1. This figure plots GS changes over time. The average of GS from this example is clearly negative, which means that according to the theory, this country is not on a sustainable path. However, the trend of the GS flow is positive, indicating that this country will eventually be on a sustainable path. Sato and Sovannroeun (2008) estimated the average trend and stability of GS during the period 1981-2005 for 84 countries, to capture not only past performance but also the future directions of a country's change in wealth. Therefore, these GS indicators deliver further information on sustainable development.

Yet, the calculation of these variables alone cannot provide insights into sustainable development. Rather, explaining why countries show different patterns of GS change is of particular interest in understanding sustainable development. This study thus attempts to identify the factors that determine the patterns in GS changes. Specifically, we investigate data on the capital and institutions of countries and regions to shed light on the relationship between wealth and institutions with regard to sustainable development. To examine the change in wealth over time, we cluster more than 80 countries based on the average, trend, and stability of GS, and the wealth level in the last 30 years. We also identify the main factors that determine long-term changes in wealth. Specifically, this study shows that the quality of institutions and population growth are important factors in identifying the path to sustainable development. Finally, we discuss feasible pathways toward sustainable development based on the patterns of capital accumulation and on these factors.

\section{Capital accumulation patterns}


Sustainability is by definition a long-term concept; thus, analyzing GS change is appropriate for its assessment. To understand the long-term performance of GS, following Sato and Sovannroeun (2008), we created three

measurements: the average, trend, and stability of GS for 80 countries for the longer period 1970-2007. Specifically, the average GS summarizes the past performance of the GS of a country $i$. That is:

The trend of GS indicates whether a country is moving toward a sustainable path:

$$
\text { Average }=\frac{1}{T} \sum_{t=1}^{T} G S_{t}
$$

$$
\text { Trend }=\frac{1}{T-1} \sum_{t=1}^{T}\left(G S_{t}-G S_{t-1}\right)
$$

Finally, the stability of GS performance is calculated based on the standard error of time-series data for the country:

$$
\text { Stability }=\left(\frac{1}{T} \sum_{i=1}^{T}\left(G S_{t}-\text { Average }\right)^{2}\right)^{1 / 2}
$$

We then carried out k-mean clustering based on the measurements in addition to the wealth level. Stability and the wealth level are included because they are able to capture the features that are not explained by the other two measurements. We tried different methods of clustering such as k-mean and k-median clustering with different numbers of $\mathrm{k}$. All of these different methods generated similar results: we conducted sensitivity analysis and obtained robust results with the same conclusions (the sensitivity analysis results are available from the authors upon request). Thus, we proceeded with our analysis based on the results of k-means clustering with $k=6$.

[Table 1 here]

Table 1 presents the profile of the six clusters. The clustered groups are arranged by their level of wealth, from high (left) to low (right) in the table, so that Group A has the highest wealth and Group F has the lowest. As for the GS variables, Group F, with the lowest wealth per capita, has by far the lowest average. Meanwhile, Groups C, D, E, and F have positive values of trend, while the two best groups (A and B) in terms of wealth have negative values. As for the stability of GS change, Group A has the least fluctuation (most stable), while Group $\mathrm{F}$ has the highest fluctuation (most unstable). The table also provides other information on each group. There are clear differences between the groups. Countries in Groups A and B have lower population growth and better institutions, whereas countries in the Groups D, E, and F have poor institutions. Furthermore, we see high population growth for countries in Groups $\mathrm{E}$ and $\mathrm{F}$ than in the other groups.

Table 2 lists the countries in each of the six groups. Group A consists mostly of OECD countries, like USA, Japan, and the EU countries, while Group B consists mainly of emerging industrialized countries with large areas, such as Australia, New Zealand, and Canada. Groups A and B are similar in their socio-economic conditions and their GS performance, although Group B shows slightly poorer performance. The other groups consist of developing countries, in which the least developed countries in Africa and South Asia tend to belong to Group F. In the next section, we show empirical evidence that institutions, population pressure, and other factors affect the patterns of capital flow.

[Table 2 here]

\section{Analysis of capital accumulation}

\subsubsection{Factors that determine accumulation patterns}

The clustering profile shows that institutions and population are related to GS flow patterns. Traditional economics considered human-made capital alone as the main factor for economic growth (e.g., Dormer, 1946). However, as Dasgupta (2007) argues, besides the accumulation of physical capital, the main factors behind economic growth are better education, health (human capital), use of science and technology, and low population growth. In fact, empirical studies in the literature on economic growth have proven that institutions and human capital are significant factors for long-term economic performance (e.g., Acemoglu and Johnson, 2005; Easterly, 2002; Hall and Jones, 1999; and Hanushek and Ludger, 2008).

By following the arguments above, our hypotheses are summarized as follows. First, the poor quality of institutions, such as lack of a strong legal framework, or the existence of corruption, probably leads to the overuse of capitals, including natural resources. It is also probable that the poor quality of institutions reduces incentives for making investments, particularly in human capital, which affects capital accumulation patterns. Furthermore, we 
claim that high population growth probably decreases the surplus of output that could have been invested in capital, thus affecting GS change. We do not include variables of human capital, such as education, because our dependent variable already contains human capital components. For the purpose of analyzing the influence of the previously explained factors on GS, we use a statistical analysis that examines the factors affecting GS change patterns.

We use a variety of data sets for this estimation. The data sources and description are summarized in the note below Table 1. For institutional variables, we use the worldwide governance indicators for the years 1996-2006. These indicators measure six dimensions of governance using six variables: Voice and Accountability, Political Stability and Absence of Violence/Terrorism, Government Effectiveness, Regulatory Quality, Rule of Law, and Control of Corruption. Since these indicators have the same range (from -2 to 2), we take an average of the six indicators across the years to obtain a single variable for institution/governance on the presumption that the quality of institutions does not change dramatically in the short or middle term. Ideally, detailed time-series data on institution/governance should be used, but unfortunately no such data are available. We also attempted to observe the effect of resource endowment on the capital accumulation pattern. The level of natural resources relative to capital stock is used as the explanatory variable. According to the curse of the natural resources hypothesis, countries rich in natural resources tend to suffer from stagnation in economic and social development as a result of the degradation of institutions and governance (Sachs and Warner, 1995). Finally, for population pressure, we calculated the average population growth rate over the period 1970-2007 for each country. We expect population growth to negatively affect capital accumulation.

\subsubsection{Regression Analysis and the Main Results}

We estimate the multinomial logit regression models to determine which factors affect the countries type in terms of the GS clustered group change. Before demonstrating the logit estimation, we first address a causal issue that was raised by growth econometric literature (Durlauf et al. 2005). This issue relates to development or economic growth that can also improve the conditions of the factors raised as determinants of development. For example, higher income could lead to the improvement of institutional quality. The common procedure to deal with causal issues is to use instrument variables (IV) procedures (Durlauf et al., 2005).

Specifically, we regress population growth and institution to wealth level in 2000 based on the IV procedure using the same dataset used in the logit model. We select two IV as the determinants of the quality of an institution: the initial value of GDP per capita (GDP per capita in 1970) and a regional dummy variable (equal to 1 if it is an African country, and equal to 0 otherwise). These two variables were used as instrument variables in the economic growth literature (e.g., Acala, 2004; Cho, 1996) and are supposed to be uncorrelated with the level of wealth. Note that we do not directly test whether our explanatory variables actually influence capital flow patterns because treatments of causality for a non-linear model with multiple discrete dependent variables have not been established.

The results of the IV regression are as follows:

$$
\text { Wealth }=200698.3^{* * *}-54205.45 \text { Pop }^{*} \text { rowth }^{* * *}+136490.1 \text { Institution }^{* * *}
$$

$$
\mathrm{N}=63 \text {, Adusted R squared }=0.7692
$$

where, numbers in the parentheses are standard errors of the IV procedure (see Chapter 5 of Wooldridge, 2002), and *** denotes statistical significance at the 1 percent level. All variables are statistically significant with the expected signs; population has a negative effect and the high quality of an institution has a positive effect on wealth. Having observed these results, we claim the validity of our logit analysis demonstrated below, in the sense that population growth and institution are used as explanatory variables of capital accumulation.

Now, the multinomial logit model determines the factors that increase or decrease the probability of a country being a member of a specific cluster. The estimated coefficients imply the log-odds ratio between the estimated cluster and the base cluster (Wooldridge, 2002). Table 3 reports the multinomial logit regression results. In the estimations, Group $\mathrm{F}$ is omitted as the base group; thus, the estimated coefficients are the log-odds ratio between the estimated group and Group F. In Model 1, in which population and institutions are the explanatory variables, most coefficients are statistically significant, with the expected signs. The positive signs of the institution variable indicate that countries with more stable institutions and/or better governance (compared with countries in Group F) are more likely to be in better clusters. Interestingly, the magnitude of the coefficients for the institution variable is larger for groups with larger wealth. In the multinomial logit model, the difference in the coefficients between the log-odds ratio of the 
two groups indicates that an institution is of better quality. Therefore, the regression result implies that (1) institutions are an important factor for all groups, and (2) better institutions are necessary for constant capital accumulation.

[Table 3 here]

The estimates of population growth are also statistically significant with negative signs. Given that countries in these clusters have poor performance in capital accumulation, high population growth generates adverse effects on capital accumulation.

Model 2 in Table 3 shows the results of the regression with the inclusion of a natural resource variable. The institution variable is omitted in Model 2 because the resource variable is a proxy for the institutional variable. The coefficients of the natural resource variable are statistically significant for Groups B, C, D, and E, and the coefficient signs are all negative, as expected. That is, the more abundant its natural resources, the less likely a country is to become a member of Group F. Furthermore, the estimates of population growth are statistically significant for most clusters. Again, that for Group E is not significant, meaning that the difference between Groups $\mathrm{E}$ and $\mathrm{F}$ is the quality of institution/governance. In summary, these results indicate that, in general, higher population growth and poor quality of institutions have negative effects on capital accumulation, although their magnitude of significance varies across different stages of development.

\section{Discussion}

Figure 2 illustrates the path of capital accumulation (wealth), in which the development stages based on the clustering are denoted. The shape of the curve in the figure reflects the GS flow patterns that we observed in Table 1. Specifically, the GS averages in Groups F and A are relatively lower than those in the middle stages; thus, in the figure the slope of the curve is flatter in the earlier stage and in the later stage of development. We have also seen that population and institutions are associated with patterns in the flow of capital; thus, they are key to sustainable development. Moving to a higher stage of development requires improvements in these factors.

Note that even countries in the best group, in terms of wealth (Group A), have negative GS trend values. This implies that even the wealth of the countries in this group will face negative GS, leading to a decrease in wealth. The figure illustrates this condition with the downward sloping dotted line. Among the countries in Group A, Norway is an exception in that it has a positive GS trend value. The relevant features of Norway are that it has a far lower population density and a relatively high natural capital stock per capita (Table 4). Thus, this case implies that the key factors necessary for sustainable development at this development stage are (1) achieving socio-economic development, (2) conserving natural capital while enhancing renewable resource utilization, and (3) reducing production and consumption levels.

[Figure 2 here]

In terms of institutions, which are the foundation of socio-economic development, our results provide insights into sustainable development for countries in Groups E and F (as we have shown). For example, Kenya, which is in Group F, in fact showed good performance in capital accumulation in the 1970s, but over a longer period was assessed as in the lowest group. The GS average for Kenya was 10.38 for 1970-89 and 7.1 for 1990-2006. Our regression results explain why this occurred: Kenya could not move up to Group E from Group F because of the poor quality of its institutions. Meanwhile Chile, which showed poor performance in GS in the 1970s, is classified as Group D in our analysis. Indeed, the GS average of Chile was -4.3 for 1970-89 and improved to 10.03 for 1990-2006. In the 1970s, Chile suffered from serious socio-economic problems caused mainly by government policies. After the political instability of the 1970s and early 1980s, Chile began an integrated reform based on the transition from a government-controlled to a free market economy while maintaining good governance, which led to steady socioeconomic development. This case clearly shows that good institutions and governance move a country to a better stage of sustainable development.

\section{Conclusion}


We analyzed countries' sustainability conditions based on the average, trend, and stability of the countries' GS flow. We identified the pattern of GS changes between 1970 and 2007 based on those three GS measures and on wealth. We then identified the factors that affect the pattern of capital accumulation. In particular, the quality of institutions and population growth, along with natural resource abundance, are the key factors in capital accumulation. Finally, we explained the sustainability pathways, based on the outcomes. In the discussion, we argued that conserving natural capital, while achieving socio-economic development through the improvement of institutions, is critical for sustainable development. In fact, we showed that in terms of the wealth level, even the most developed countries are not on a sustainable path. These results are not only consistent with the literature in economics, but also provide more insights into the context of sustainable development.

\section{Acknowledgments}

This work was supported by the Ministry of Education, Culture, Sports, Science and Technology (MEXT) of Japan through Special Coordination Funds for Promoting Science and Technology, as part of the flagship research project "Development of an Asian Recycling-Oriented Society."

\section{References}

Acala F. and Ciccone A., 2004. Trade and productivity. Quart. J. Econ. 119, 613-646.

Acemoglu D. and Johnson S., 2005. Unbounding institutions. J. Polit. Econ. 113, 949-995.

Barry N., Urbel-Piirsalua E., Stefan A., and Lennart O., 2007. Categorizing tools for sustainability assessment. Ecolog. Econ. 80, 498-508.

Cho D., 1996. An alternative interpretation of conditional convergence results. J. Money, Credit, Banking. 28, 669681.

Durlauf S., Johnson P., and Temple J., 2005. “Growth econometrics” in Aghion P., and Durlauf S., (Eds), Handbook of Econometric Growth.

Dasgupta P., 2007. Measuring sustainable development: theory and application. Asian Devel. Rev. 24, 1-10.

Dasgupta P., 2001. Human well-being and the natural environment. Oxford University Press.

Domer E. D., 1946. Capital expansion, rate of growth, and employment. Econometrica, 14, 137-147.

Easterly W., 2002. The elusive quest for growth: economists' adventures and misadventures in the tropics. The MIT Press.

Ekins S., Dresner S., and Dahlstrom K., 2008. The four capital method of sustainable development evaluation. Europ. Environ. 18: 63-80.

Esty C. D., Levy M., Srebotnjak, T., and Sherbinin A., 2005. 2005 Environmental sustainability index: benchmarking national environmental stewardship. Yale Center for Environmental Law \& Policy, New Haven.

Global Footprint Network, http://www.footprintnetwork.org/

Hall E. R. and Jones C., 1999. Why do some countries produce so much more output per worker than others?. Quart. J. of Econ. 114, 83-117.

Hanushek E., and Ludger W. 2008. The role of cognitive skills in economic development. J. Econ. Lit. 46, 607-668. 
Kaufmann D., Klaay A., and Matruzzi M., 2008. Governance matters VII aggregate and individual governance indicators 1996-2007, Policy Research Working Paper, The World Bank Development Research Group Macroeconomics and Growth Team \& World Bank Institute Global Governance Program.

Pearce D., and Atkinson G., 1993. Capital theory and the measurement of weak sustainability. Ecolog. Econ. 8, 103108.

Pillarisetti T J.R., 2005. The World Bank's 'genuine savings’ measure and sustainability. Ecolog. Econ. 55, 599-609.

Neumayer E., 2003. Weak versus strong sustainability: exploring the limits of two opposing paradigms. Second Edition, Edward Elgar, Cheltenham, UK.

Sachs J. D., and Warner A. M., 1995. Natural resource abundance and economic growth, NBER Working Paper 5398.

Sato M., and Sovannroeun S., 2008. Assessing sustainable development by genuine saving indicator from multidimensional perspectives. MPRA, Munich.

Wackernagel M., and Rees W. E., 1996. Our ecological footprint: reducing human impact on the earth. New Society Publishers, Gabriola Island, Philadelphia. 